\title{
JOGOS DIGITAIS COMO FERRAMENTA DE ENSINO: REFLEXÕES INICIAIS
}

Fernando da Silva ${ }^{1}$

Sandro Brincher ${ }^{2}$

\section{INTRODUÇÃO}

Como professores tanto do ensino médio quanto do ensino superior, e principalmente como adultos cuja formação enquanto indivíduos foi, de alguma forma, permeada pelo universo dos jogos digitais, sempre nos perguntamos por que estes ainda não são efetivamente utilizados como ferramenta de ensino? É possível perceber claramente alguns indícios positivos de possibilidade desse uso: a profusão cada vez maior de títulos, plataformas, gêneros, modos de jogabilidade e convergência de mídias; a popularidade dos jogos tanto entre crianças quanto entre adultos; a grande quantidade de iniciativas de produção de jogos com fins educacionais; o aumento significativo nas ofertas de financiamento de projetos dessa natureza, seja através de agências estatais de fomento, seja através da iniciativa privada. Entretanto, há também contrapontos em relação a essa aparente facilidade: os jogos ofertados atendem à demanda dos professores e à demanda de um componente curricular específico? As instituições educacionais possuem condições técnicas e recursos humanos capacitados para tal? O aparente descompasso entre gerações - o professor nem sempre é ou foi um jogador e, por isso, sua familiaridade com esse universo é meramente tangencial - configuraria impedimento para a efetiva implementação de uma proposta dessa natureza? Como escolher - e onde obter - os jogos necessários a diferentes objetivos educacionais?

O presente artigo não tem a pretensão de responder a todos esses questionamentos. Todavia, tentará dar conta de pelo menos algumas questões cruciais para se discutir com mais profundidade a utilização de jogos como agentes modificadores nas práticas de ensino e aprendizagem de componentes curriculares, buscando mostrar como essa prática pode oferecer subsídios consistentes para a consolidação de uma prática pedagógica significativa. Resumidamente, trataremos do jogo como elemento de significação, associando esse aspecto a algumas teorias correntes sobre jogo e aprendizado e discutindo formas de associação entre jogos digitais e planejamentos curriculares. Ao fim do artigo, apresentamos uma lista com alguns recursos (jogos; produtoras; instituições; núcleos de pesquisa) úteis para a efetiva implementação dessa proposta.

\footnotetext{
1 Bacharel em Letras-Inglês e Mestre em Pós-Graduação em Estudos da Tradução pela Universidade Federal de Santa Catarina (2010), leciona na Universidade Comunitária da Região de Chapecó. fe900571@gmail.com

${ }^{2}$ Licenciado em Letras-Português e Mestrando em Teoria da Literatura na UFSC, atua como tutor no Ensino a Distância (Letras-Português/UFSC) e leciona Literatura e Redação no Ensino Médio. sandrobrincher@gmail.com
} 


\subsection{Princípios fundamentais para uso instrucional de jogos}

Segundo Moita (2006), por serem muitos deles concebidos de forma semelhante a situações ficcionais de aprendizado utilizadas em sala de aula, os jogos são muita vezes mais efetivos na consolidação de uma proposta de ensino contextualizado. Segundo a mesma autora, o jogo se apresenta como uma atividade na qual, por sua própria natureza, coexistem de forma antagônica várias características que constituem elementos de formação de conhecimento e de identidade do sujeito.

Para Gee (2009), citado por Moita (ibid), o jogo oferece ao aprendiz artefatos que incrementam seu potencial de aprendizado de forma crítica e ativa. Através de estímulos que utilizam textos multimodais ${ }^{3}$, comprovadamente eficazes como forma de retenção de conhecimento, os resultados do aprendizado são maximizados por conta dos diferentes estímulos. Para a concepção de jogos para o uso instrucional deve incorporar alguns princípios básicos relacionados ao aprendizado.

Identidade: Para um aprendizado efetivo de um novo domínio de conhecimento, seja este física ou decoração de interiores, é importante que o aprendiz se posicione e assuma o papel de um novo sujeito. $\mathrm{O}$ aprendiz/jogador deve se comprometer durante o jogo a enxergar e interagir com o mundo que se desdobra diante de si da mesma forma que um físico ou um decorador de interiores. Esta caracterização pode ser feita através da customização de um avatar ${ }^{4}$ ou através da constituição do caráter de uma personagem através de suas ações dentro de um jogo.

Interação: Diferente da interação obtida com livros, comumente de forma passiva. Sem a possibilidade de obter uma avaliação imediata, jogos oferecem ao aprendiz a possibilidade de dialogar com um conteúdo instrucional específico de forma a obter retorno para qualquer ação dentro do jogo. Além do retorno dado ao jogador aprendiz, o conteúdo apresentado é executado de forma contextualizada e através de elementos de comunicação multimodais.

Produção: O jogador/aprendiz não deve ser apenas um consumidor do que o jogo pode lhe oferecer, mas produtor e co-autor de seu jogo através de opções de personalização de níveis e de personagens.

Risco envolvido: Bons jogos devem oferecer ao jogador/aprendiz a possibilidade de negociar as conseqüências de seus erros. Esta característica é representada pela possibilidade de retomar o progresso do jogo em caso de insucesso em um nível ou desafio específico, encorajando o jogador dessa forma a progredir e explorar o jogo através do método de tentativa e erro e a compreender as conseqüências de suas ações.

\footnotetext{
${ }^{3}$ Os textos multimodais são, segundo o autor, aqueles que combinam palavras e imagens, ou seja, modos distintos de se estabelecer uma comunicação. Dependendo do tipo de suporte físico (filmes; jogos etc.), entretanto, podemos ter muitas outras combinações, não apenas palavras e imagens.

4 Ícone gráfico utilizado por um usuário para representá-lo em determinados jogos, comunidades virtuais e redes sociais.
} 
Aprendizado situado: o aprendizado acontece em função da atividade que se executa, do contexto em que esta está inserida e do universo cultural do jogador (ou mesmo do próprio jogo), e se dá eminentemente através da prática do jogo. (GEE; 2009:4) ${ }^{5}$

Segundo Whitton (2010), ao concebermos o uso de jogos digitais que visam ao aprendizado, diferentes abordagens devem ser adotadas para adultos e crianças, uma vez que o envolvimento de cada um desses grupos em interações lúdicas educacionais é desenvolvido a partir de objetivos e estratégias distintas. Devem ser consideradas, por exemplo, diferentes variáveis de aprendizado, como o grau de familiaridade de um sujeito com tecnologias, sua motivação, a prática de aprendizado reflexivo que a atividade lúdica em questão desenvolve, entre outros elementos. Antes de nos aprofundarmos nessa discussão, convém que estabeleçamos alguns conceitos fundamentais inerentes a algumas das teorias sobre desenvolvimento e aplicação de jogos digitais para fins de aprendizado que nortearão este trabalho.

Mesmo com a evidente dificuldade - e, em termos de estratégia argumentativa para a confecção deste texto, pouca utilidade - em se estabelecer claramente uma definição para o termo jogo, significante cujos significados extravasam os limites do campo teórico sob o qual nos abrigamos aqui e que flerta abertamente com inúmeras outras áreas, passaremos agora a uma breve recapitulação do conceito a partir de pontos de vista que julgamos compatíveis com a presente proposta.

Em Homo ludens (publicado em 1938), considerada por Roger Caillois "a obra mais importante na filosofia da história em nosso século" ", Johan Huizinga trata o jogo a partir de uma perspectiva sócio-cultural, estabelecendo-o como elemento que precede inclusive a própria cultura, já que esta pressupõe uma sociedade humana, enquanto aquele é parte constituinte até mesmo da vida dos animais.

Huizinga diz que o jogo, nos relaciona de maneira inerente e visceral a nossa humanidade, pois abarca as esferas mais importantes da existência humana, como a Arte, o Conhecimento, a Filosofia, a Poesia, a Guerra e o Direito.

A existência do jogo não está ligada a qualquer grau determinado de civilização, ou a qualquer concepção do universo. Todo ser pensante é capaz de entender à primeira vista que o jogo possui uma realidade autônoma, mesmo que sua língua não possua um termo geral capaz de defini-lo. A existência do jogo é inegável. É possível negar, se se quiser, quase todas as abstrações: a justiça, a beleza, a verdade, o bem, Deus. É possível negar-se a seriedade, mas não o jogo. (1994:6)

\footnotetext{
5 Tradução nossa.

${ }^{6} \mathrm{Da}$ contracapa da edição aqui citada.
} 
O pensamento de Huizinga inaugurou o estudo dos jogos a partir de um ponto de vista radical e que até então não havia sido devidamente explorado, qual seja o do jogo como elemento fundador da cultura. Para ele, "a antropologia e as ciências a ela ligadas têm (...) prestado muito pouca atenção ao conceito de jogo e à importância fundamental do fator lúdico para a civilização".

Já na metade do séc. XX - mais precisamente em 1957, com Les jeux et les hommes -, o francês Roger Caillois irá desenvolver uma Sociologia cujo foco se centra principalmente numa questão crucial, “Haverá tudo saído do jogo?” (1994:108), originada justamente a partir do Homo ludens. Pouco mais de duas décadas depois, Giorgio Agamben proporá, em seu Infanżia e storia (1979), que a história é, em suma, a relação entre jogo e rito, ou entre os significantes sincrônicos e diacrônicos que estes produzem constantemente.

Nos anos recentes, o crescente avanço da indústria de jogos eletrônicos fez surgir estudos cada vez mais específicos em torno do jogo, sobretudo de seus usos. Esse crescente campo teórico, que vem sendo chamado de game studies ${ }^{7}$, é também um dos norteadores deste trabalho. Poupamo-nos de apresentar dele uma - mesmo breve - genealogia não somente por sua hiperatualidade, mas também porque sua definição como área do saber ainda é bastante discutida. O contexto, esperamos, dará conta de esclarecer a forma pela qual o estamos tomando.

\subsection{Jogo como elemento de significação}

Um primeiro passo necessário para a compreensão do uso de jogos eletrônicos como instrumento de aprendizado é aceitar sua função como uma prática significativa, como elemento formador de e constituído por significados. Segundo Huizinga,

(...) o jogo é mais do que um fenômeno fisiológico ou um reflexo psicológico. Ultrapassa os limites da atividade puramente física ou biológica. É uma função significante, isto é, encerra um determinado sentido. No jogo existe alguma coisa "em jogo" que transcende as necessidades imediatas da vida e confere um sentido à ação. Todo jogo significa alguma coisa. (2000:5)

Assim como os mitos, narrativas e cosmogonias são capazes de explicar aspectos importantes de uma dada cultura - origem ou criação do universo; aparecimento de fenômenos naturais; formação de acidentes geográficos etc. -, os jogos são igualmente capazes de criar, cristalizar ou mesmo reinventar significados, justamente porque "da mesma forma que estórias

\footnotetext{
${ }^{7}$ Por sua ampla difusão no meio acadêmico, optarmos pelo termo em Inglês.
} 
nos ajudam a atribuir significado aos diferentes eventos de nossas vidas, os jogos também o fazem $^{8}$ (Derryberry; 2010); conforme Simkins \& Steinkuehler, os jogos não são instâncias alheias à vida cotidiana, são "espaços criadores de significação" constitutivos dela. Mesmo que modifiquem "as regras tradicionais de interação social", não as desprezam ou negam-lhe consequências no jogo mesmo (2008:338). ${ }^{9}$

Ao aceitarmos o argumento de que o jogo é, por definição, um elemento de significação, podemos também associá-lo a conceitos relacionados à educação, como o de prática significativa e o de aprendizado significativo. Segundo Pelizzari et al (2002), para que uma prática de aprendizagem significativa se desenvolva, é necessário que se entenda o processo de modificação do conhecimento e a forma pela qual os processos cognitivos se relacionam com a construção do saber. Ainda segundo as mesmas autoras - balizadas nas formulações do psicólogo estadunidense D. P. Ausubel -, para que uma prática de aprendizado significativo se consolide, é necessário que duas condições fundamentais sejam aceitas: 1) o aluno precisa estar motivado para aprender; do contrário todo o seu aprendizado será encaminhado de forma mecânica; 2) o conteúdo deve chegar e ser percebido pelo aluno de forma significativa, de maneira a fazer sentido e permitir a construção de relações de significação.

Segundo Salen e Zimmerman (2004), desenvolver jogos educativos que possuam significado e que, mais importante - porque o significado é hoje visto como descentralizado, fluido, múltiplo e dependente do leitor/espectador/jogador -, sejam significativos, tornou-se um dos grandes desafios para game designers. O conceito de jogo significativo, segundo os mesmo autores, pode ser construído de duas maneiras distintas ${ }^{10}$, dependendo da maneira como emergem durante a interação. Em qualquer das formas, o jogo deve incluir processos de tomada de decisão para a consolidação de um processo de aprendizado, onde cada ação tomada pelo jogador-aprendiz deve estar relacionada a um sistema de representação de significados ligado ao conteúdo específico a ser ensinado. Este conteúdo pode, assim como em tarefas relacionadas a jogos eletrônicos, ser executado através de etapas, que ajudem o jogador-aprendiz a mapear e monitorar seu processo de construção do conhecimento.

Considerando que um jogo se constitui como um universo representacional no qual o jogador interage através de $n$ elementos e ações encaminhadas e geridas por uma narrativa que guiará o jogador através de uma interação lúdica significativa, é de se notar o papel determinante de uma história (estória) no próprio conceito de jogo. De acordo com Miller (1990) apud Salen e

\footnotetext{
$8 \quad$ No original: "Just as stories help us discover meaning in life's events, so, too, can games."

No original: (...) "rather than focusing on the game as something outside of life, we should understand games as meaning generating spaces within life. In games, ordinary rules of social interaction are changed, but that does not mean they are not important and consequential”.

${ }^{10}$ Os autores utilizam os conceitos de jogo significativo discernivel e integrado.
} 
Zimmerman (2004:385), através de uma narrativa podemos ordenar e reordenar o que nos é apresentado como experiência. A narrativa nos possibilita dar à experiência uma forma e um significado únicos.

Em se tratando de jogos digitais, as diferenciações básicas entre estruturas narrativas dependem de seu grau de inserção e de como se manifestam no jogo. Se, de um lado, há narrativas que já acompanham o jogo desde sua concepção, funcionando como uma espécie de roteiro, há do outro aquelas que são delineadas a partir das ações do jogador, de sua experiência no jogo e dos resultados que ele obtém dessa experiência. A estas duas dimensões narrativas chamamos, respectivamente, narrativa emergente e narrativa embutida.

Independente de qual das estratégias será empregada, parece evidente não apenas que se deve utilizar uma linha narrativa que fundamente a experiência do jogo, mas também que essa narrativa seja suficientemente consistente para manter o jogador imerso nele. Uma narrativa bem estruturada é, portanto, crucial para outro fundamento do game design: a imersão. Esta pode ser entendida, grosso modo, como a projeção do jogador (de seu corpo, experiências e memórias) num dado universo ficcional - seja ele pictórico, escrito ou eletrônico. Na original abordagem de Ryan (2001), por exemplo, que se ancora num vasto repertório de textos literários, a imersão não é apenas associada à narrativa, mas parte indispensável desta. A questão da imersão é tão importante para a autora que recebe um capítulo exclusivo sob a alcunha de Poética da Imersão o "Poética" ali é uma clara referência àquela bem conhecida Poética de Aristóteles.

De qualquer modo, não é apenas as questões de significação, imersão e fruição lúdica que se colocam como desafios no que tange à utilização de jogos eletrônicos para fins educativos. Outro procedimento bastante complexo é o de aliar, de maneira consistente, as principais teorias educacionais vigentes às teorias de design de jogo. Não se trata de necessariamente criar novas teorias educacionais, já que, de alguma maneira, as existentes estão, em seus devidos contextos e ressalvadas as suas críticas, funcionando, mas simplesmente de, a partir das teorias de game design, organizar uma nova (ou renovada) interface metodológica.

Tal interface também serve para estabelecer diretrizes de ensino e aprendizado através de jogos de maneira a definir metas e tornar viável o assessoramento de todos os processos relacionados a uma prática de ensino. A triangulação entre assessoramento, metas de aprendizado e atividades desenvolvidas é chamada por Biggs (2003) apud Whitton (2010:31) de alinhamento construtivo.

Uma concepção errada também presente no discurso da educação a distância, sobretudo se dermos mais atenção ao discurso de aprendizado mediado por computador, é acreditar que o aprendizado através de jogos digitais se dá ou é encaminhado única e exclusivamente pelo aluno. 
Ainda que os processos de aprendizado autônomo sejam utilizados com mais freqüência dentro desta abordagem de aprendizado, o conceito de interação entre pares é também um componente de suma importância para a consolidação do aprendizado de conteúdos instrucionais. A interação entre pares oferece ao aprendiz instrumentos para a identificação de problemas de aprendizado através de uma pratica de reflexiva comparada. A presença de um feedback é componente fundamental na construção de conhecimento, pois possibilita ao aluno identificar seus erros e observar diferentes perspectivas acerca do que é ensinado (WHITTON; 2010:36).

Um ponto muito importante, segundo a mesma autora (2010:36), é o fato de que a maioria dos estudos relacionados ao uso de jogos como instrumento de aprendizado foram ou são encaminhados através da observação de grupos de crianças, sob a premissa - implícita ou explícita - de que as mesmas estratégias podem ser aplicadas para grupos de adultos. Da mesma forma que as estratégias utilizadas para educação diferem de acordo com as faixas etárias do público alvo, a percepção do jogo por ambos os grupos também é distinta. Knowles (2005) ${ }^{11}$, em seu estudo relacionado à educação de adultos, referido como Andragogia, estabelece alguns princípios básicos que distinguem o comportamento de crianças e adultos durante o aprendizado. Para Knowles, a educação de adultos caracteriza-se pelo uso de processos de aprendizado autônomos, que lhes permitem um maior controle de suas ações na construção do conhecimento. Knowles (2005:4) estabelece os postulados fundacionais dessa teoria:

- $\quad$ Adultos precisam saber o porquê de precisarem aprender algo novo antes que se disponham a investir tempo e energia para tal tarefa; precisam ter um propósito claro para seu aprendizado.

- Adultos precisam estar em controle de seu próprio aprendizado de maneira a estabelecer o que, onde, quando e como devem estudar. Adultos devem poder compreender como se dá seu processo de aprendizado. Para o adulto a abordagem de ensino deve ser centrada no aprendiz tão logo este se torne autônomo de seu aprendizado

- Para o adulto as atividades desenvolvidas para o aprendizado devem contemplar e considerar seu conhecimento prévio, suas experiências, sua diversidade, como forma de construir significado para um conteúdo instrucionado.

- $\quad$ Adultos se prontificam a aprender quando vêem que precisam aplicar uma habilidade ou conhecimento específico em situações do mundo real. A aplicação de um conteúdo instrucional no mundo real é de fundamental importância para estabelecer uma relação associativa entre conhecimento e habilidade.

- $\quad$ O aprendizado de adultos é melhor encaminhado se executado através de tarefas, onde objetivos claros de aprendizado são estabelecidos de antemão. ${ }^{12}$

Fica claro neste momento que além do conteúdo utilizado para o desenvolvimento de um jogo com fins educacionais, seu conteúdo instrucional e a maneira como será abordado, é

\footnotetext{
11 Publicado pela primeira vez em 1973.
}

12 Tradução nossa. 
necessário também adequar o jogo a uma faixa etária específica. Para tal, segundo Whitton (2010:41), o desenvolvimento de jogos educativos deve contar com princípios pedagógicos sólidos, orientados a partir de um arcabouço teórico consistente de aprendizado e ensino.

\section{JOGO E APRENDIZADO}

A aplicação de plataformas de jogos para fins de instrução e aprendizado, bem como jogos em si, demonstra um uso crescente com objetivos outros que não o puro entretenimento. Através de enumeras iniciativas e pesquisas orientadas a partir de diferentes aparatos metodológicos e teóricos consistentes, observa-se uma aplicação crescente de tais instrumentos não só para a educação de infantil, mas igualmente e maneira significativa, para a educação de alunos em nível superior. Esta aplicação, de acordo com Conolly et al. (2009), deve ser estruturada através de princípios teóricos embasados de ensino e aprendizagem de forma a maximizar o real potencial dos jogos digitais como uma prática de aprendizado construtivista. Para os mesmos autores, dentro de ambientes virtuais de aprendizado, o aprendiz pode experimentar graus de envolvimento distintos do que poderia em um ambiente tradicional de aprendizado. Através desses ambientes, o aluno pode construir seu saber através, por exemplo, de um envolvimento identitário como o conteúdo instrucionado, criando assim um sentido de autenticidade e identificação com o conteúdo que se propõe ensinar.

Para Conolly et al. (2009:22), dentro de um aparato teórico construtivista, a aplicação de jogos digitais deve estimular a relação entre o conhecimento prévio do alunos através de seu envolvimento com um contexto de interação autêntico ou simulado, assim como é observado em jogos digitais. Esta relação, de acordo com Savery e Duffy (1995) apud Conolly et al. (2009:22), se constrói a partir de três princípios fundamentais de acordo com o arcabouço teórico de aprendizado construtivista: a noção de envolvimento cognitivo situado, onde o aprendiz através de sua relação com o conteúdo instrucionado, seu contexto social e identitário e suas ações em um ambiente virtual, estrutura sua prática de aprendizado; questionamento cognitivo, também chamado de conflito cognitivo, caracteriza-se por oferecer ao aprendiz o estimulo motivacional necessário para este organize e objetive suas ações de aprendizado por conta de um conflito de ordem lógica ou narrativa; e por último, e talvez o elemento determinante e que distingue uma pratica de aprendizado baseada em jogos eletrônicos de outras práticas formais, o engajamento social, onde o conhecimento se constrói através da relação e interação do aprendiz com seus pares. Este último oferece ao aluno a oportunidade de questionar suas praticas em tempo real a 
partir de uma visão comparada de suas ações, isto é, através de do engajamento com outros jogadores em um ambiente virtual o aprendiz tem a oportunidade de testar e compreender os diferentes posicionamentos relacionados a construção de seu saber (WHITTON, 2010).

Cada jogo é identificado através de diferentes características, que validam ou não sua aplicação como ferramenta de aprendizado e ensino em diferentes áreas de conhecimento. Muitas dessas características, assim como em outras formas de interação multimidiática, se sobrepõem, tornando por vezes indistinguível o limite entre um e outro gênero ou seu objetivo de aprendizado. É importante que se destaque que invariavelmente todos os jogos podem apresentar benefícios e malefícios, mesmo para uma prática orientada de aprendizado, fato que demonstra a necessidade de uma objetivação clara dos propósitos de aprendizagem, bem como seu processo de desenvolvimento.

Para Whitton (2010:56), é importante destacar que os objetivos de aprendizado não se orientam única e exclusivamente a assimilação de conteúdos programáticos, como matemática, química, biologia, entre outros, mas também à assimilação de habilidades cognitivas paralelas como antes citadas, igualmente válidas de serem exploradas (ex.: coordenação motora, raciocínio lógico, orientação espacial, engajamento social, formação identitária etc.).

Gagné (et al; 1992) apud Whitton (2010:25) identifica cinco categorias principais de aprendizado que podem ser exploradas de maneira construtiva dentro do contexto de educação superior $^{13}$ :

\begin{tabular}{|l|l|}
\hline \multicolumn{1}{|c|}{ Categoria } & \multicolumn{1}{|c|}{ Descrição } \\
\hline Habilidade de intelecto & $\begin{array}{l}\text { Esta categoria relaciona-se a distinção de conceitos, regras e relações } \\
\text { lógicas (ex.: através do uso de álgebra ou execução de jogos que exijam } \\
\text { raciocínio matemático) }\end{array}$ \\
\hline Estratégia cognitiva & $\begin{array}{l}\text { Estratégias relacionadas ao planejamento e a execução de processos } \\
\text { cognitivos. }\end{array}$ \\
\hline Informação verbal & $\begin{array}{l}\text { Estabelecer uma relação entre fatos e conceitos específicos (ex.: jogos que } \\
\text { objetivem o ensino dos conteúdos programáticos de geografia, biologia, } \\
\text { história etc.) }\end{array}$ \\
\hline Habilidade motora & $\begin{array}{l}\text { Jogos que demandem a execução de seqüências e movimentos específicos } \\
\text { para que se alcance um objetivo (ex.: jogos de dança e exergames }\end{array}$ \\
\hline Atitude & $\begin{array}{l}\text { Jogos que incentivem posicionamentos ideológicos e sistemas de crenças } \\
\text { embasados (ex.: jogos persuasivos ou jogos com conteúdos ideológicos } \\
\text { marcados) }\end{array}$ \\
\hline
\end{tabular}

Tabela 1 - Principais categorias de aprendizado

\footnotetext{
13 Tradução nossa.

${ }^{14}$ Jogos que são também uma forma de exercício físico. O console Nintendo Wii ${ }^{\circledR}$ tem popularizado esse segmento através do dispositivo Kinect ${ }^{\circledR}$, que permite a repetição, no jogo, de movimentos reais feitos pelo jogador. O gênero começou sua popularização, entretanto, no final dos anos 90 com Dance Dance Revolution, da fabricante Konami ${ }^{\circledR}$.
} 
Feitas essas considerações iniciais a respeito das teorias que envolvem a utilização de jogos no aprendizado de adultos, passaremos à discussão a respeito da associação entre os jogos propriamente ditos, as teorias supracitadas e os componentes curriculares aos quais tais elementos deverão estar subordinados.

\section{COMO ASSOCIAR O USO DE JOGOS DIGITAIS A UM COMPONENTE CURRICULAR?}

A tarefa de associar uma prática de aprendizado lúdica baseada em jogos digitais a um componente curricular específico abrange inúmeros desafios metodológicos e teóricos, como vimos acima. Ao admitirmos a proposta de uso de jogos para o ensino e o aprendizado, devemos observar uma série de elementos que distinguem o que é encarado como um simples jogo de uma proposta integralmente alinhada a um objetivo curricular específico. Isso se deve ao fato de que jogos digitais sem propósitos educacionais específicos possuem muitos elementos de interatividade em comum com sua respectiva contraparte - os jogos digitais educativos. Todavia, pelas diferenças consideráveis em seu processo de criação, objetivos e possibilidades, seu uso deve ser encarado de maneira distinta para que os objetivos educacionais sejam efetivamente alcançados.

Para Conolly et al (2009:4), o conceito de jogo significativo, ou aquele que se propõe a ensinar, emerge de maneira a objetivar uma prática que promove a formação de novos conceitos e, em paralelo, o desenvolvimento de diferentes habilidades cognitivas. Tal proposta deve ser executada a partir de novas concepções acerca do que se refere como jogo e como mídia de entretenimento, com suas regras e objetivos específicos de aprendizagem, que interagem de maneira distinta com outros conceitos compartilhados com jogos sem o mesmo fim, compondo assim um conjunto de características que refletem e sustentam um propósito consistente de aprendizagem. Segundo Conolly (2009:5), a real distinção entre o que é tomado como jogo educativo e o que se refere como play na língua inglesa (um jogo sem objetivos de aprendizado) se dá a partir de alguns elementos fundamentais. Na tabela abaixo, reproduzida integralmente do texto de Conolly ${ }^{15}$, podemos visualizar as diferenças referentes a essas duas abordagens lúdicas:

Jogos sem objetivos de

Jogos educativos

15 Tradução nossa. 


\begin{tabular}{|c|c|c|}
\hline & aprendizado & \\
\hline Propósito & $\begin{array}{l}\text { Para propósitos } r \\
\text { entretenimento apenas. Seu } \\
\text { universo ficcional, em geral, é } \\
\text { fantasioso e baseado em } \\
\text { elementos de significação } \\
\text { fictícios. }\end{array}$ & $\begin{array}{l}\text { Para propósitos de aprendizado e desenvolvimento de } \\
\text { habilidades específicas. Seu universo ficcional pode ser } \\
\text { baseado em elementos de significação reais (fatos, } \\
\text { dados etc.) ou fantasiosos. }\end{array}$ \\
\hline Jogo (play) & $\begin{array}{l}\text { A Interação é pensada } \\
\text { primariamente para fins de } \\
\text { entretenimento através de } \\
\text { objetivos direcionados a partir de } \\
\text { elementos de significação de } \\
\text { ordem narrativa (textos, diálogos } \\
\text { etc.). A Interação (ações, física } \\
\text { etc.) é executada de forma a } \\
\text { assemelhar-se superficialmente ao } \\
\text { mundo real. }\end{array}$ & $\begin{array}{l}\text { A interação é pensada de forma a estimular o } \\
\text { aprendizado através de ações significativas e objetivos } \\
\text { de aprendizado mensuráveis. O conhecimento ou } \\
\text { conteúdo instrucional específico é inserido e exposto } \\
\text { no jogo através de interações e diálogos. Em alguns } \\
\text { casos, a Interação (ações, física etc.) é executada de } \\
\text { forma a ser fiel ao mundo real. }\end{array}$ \\
\hline Regras & $\begin{array}{l}\text { As regras são estabelecidas de } \\
\text { forma a dar controle às ações do } \\
\text { jogador e, em geral, refletem } \\
\text { aspectos de jogabilidade dentro } \\
\text { de seu próprio contexto, e não } \\
\text { referentes ao mundo real. }\end{array}$ & $\begin{array}{l}\text { As regras são estabelecidas de forma a conduzir } \\
\text { objetivos de aprendizado específicos que são } \\
\text { mensuráveis durante o jogo. As regras podem ser } \\
\text { complexas ou simples e servem primordialmente para } \\
\text { dar suporte ao jogo, ou seja, são subordinadas a ele. }\end{array}$ \\
\hline $\begin{array}{l}\text { Concepções acerca das } \\
\text { crenças, normas e } \\
\text { ambiente de jogo }\end{array}$ & $\begin{array}{l}\text { Crenças, normas e ambiente são } \\
\text { apresentados visualmente através } \\
\text { de narrativas que são, em sua } \\
\text { maioria, representadas em } \\
\text { mundos imaginários, retratados } \\
\text { de maneira hiperbólica. }\end{array}$ & $\begin{array}{l}\text { Crenças, normas e ambiente são representados } \\
\text { visualmente através de narrativas relacionadas a um } \\
\text { domínio de conhecimento específico. Estas narrativas } \\
\text { são produzidas com verossimilhança e tem uma relação } \\
\text { direta e explícita com o mundo real. O ambiente de } \\
\text { jogo pode, entretanto, se passar em um mundo } \\
\text { imaginário. }\end{array}$ \\
\hline
\end{tabular}

Tabela 2 - Diferenças entre duas abordagens lúdicas

Os elementos acima citados representam parte do que se considera relevante no processo de desenvolvimento de jogos que visam ao ensino de conteúdos específicos. Estruturados de maneira a validar uma experiência de jogo consistente e justificados por objetivos pedagógicos claros, a utilização de jogos educativos, de acordo com Conolly (2009:31), deve ser sustentada não apenas por ser uma proposta lúdica e, considerando o modelo tradicional de ensino, inovadora em sala de aula, ou porque representam uma ferramenta de motivação - por seu apelo popular como ferramenta de aprendizado -, mas por seu alinhamento a objetivos claros em uma estrutura curricular. Em outras palavras, não se trata de transformar conteúdo em joguinho com a desculpa de tornar aquele mais atraente, mas considerar que essa passagem do meramente textual, por exemplo, ao lúdico implica muito mais que uma mera mudança de suporte. Em outras palavras, não se trata de transformar conteúdo em joguinho com a desculpa de tornar aquele mais atraente, mas considerar que essa passagem do textual, por exemplo, ao lúdico implica muito mais que uma mera mudança de suporte.

O crescente aumento de interesse nessa aliança entre jogos e ensino tem estimulado a criação de grupos de debates e pesquisa mundo afora, seja através de instituições ou de grupos de 
indivíduos sem um estrito vínculo institucional. No Brasil, a maior parte das iniciativas está centrada na área da pesquisa acadêmica, com estudos financiados majoritariamente por agências de fomento como CAPES, CNPq e afins. Para McConnell (2006:11) apud Conolly (2010:24), são os recursos de interação colaborativa disponibilizados por muitos deles - tanto os que possuem objetivos de aprendizado quanto os de entretenimento - que possibilitam o surgimento de verdadeiras comunidades voltadas ao aprendizado e ao compartilhamento de conhecimento, experiências e responsabilidades acerca de estratégias de ensino e aprendizado lúdico. Adiante citaremos algumas dessas iniciativas, nacionais e internacionais, institucionais ou não, com seus respectivos endereços online.

Ancorada num movimento de afastamento do que é compreendido como método tradicional de ensino e aprendizado, uma aproximação entre metodologias de ensino colaborativo como o que ocorre, por exemplo, nas chamadas comunidades virtuais - vem ganhando mais aplicação em ambientes formais de educação. De acordo com Conolly (2010:23), o colaborativismo é um conceito chave na elaboração de jogos com propósitos educativos, já que a prática de ensino colaborativa se relaciona de maneira consistente com alguns princípios norteadores das práticas de ensino construtivistas.

Para Grabinger et al (1997), o aprendizado construtivista deve ser sustentado por práticas sociais compartilhadas e orientadas. O aprendizado é um processo colaborativo no qual o aluno assimila conhecimentos não apenas individualmente, mas através de sua interação entre pares. Da mesma maneira que em ambientes de aprendizado formais, balizados por práticas de aprendizado compartilhadas, em ambientes virtuais é oferecida ao aprendiz/jogador a oportunidade de construir conhecimento através da interação com as experiências e necessidades de outros jogadores, criando assim, a partir dessas ações, responsabilidades acerca de seu próprio saber.

Whitton apud Conolly (2010:18) sugere que alguns princípios referentes ao arcabouço teórico e metodológico de game design devam ser seguidos de maneira a otimizar a experiência de aprendizado do aprendiz/jogador. Para a autora, é crucial que se perceba que os elementos constitutivos de uma experiência efetiva de aprendizado - não necessariamente baseada em jogos - sejam igualmente considerados em uma abordagem que contemple o uso de jogos.

Para que tais experiências sejam implementadas de maneira clara e eficiente, alguns critérios relacionados a interface e jogabilidade de interações educativas baseadas em jogos devem ser estabelecidos. Whitton, citado por Conolly (2010:29) estabelece os seguintes critérios seguidos de seus respectivos exemplos para que esta interface seja executada de maneira a maximizar os objetivos de aprendizado propostos: 
- Interação flexível: o educador deve certificar-se que toda a interação possua um propósito específico; todo feedback para o aprendiz/jogador deve ser apresentado de maneira significativa e tão logo a atividade seja executada; controles devem ser apresentados de maneira lógica e consistente; apresentar indicadores de performance durante o jogo.

- Suporte a interação de forma colaborativa: oferecer ao jogador/aprendiz a possibilidade de comunicação entre pares ${ }^{16}$; oferecer a funcionalidade de autoregulamentação (gerenciamento de privilégios de comunicação pela própria comunidade); oferecer a possibilidade de criação de avatares ou outros recursos de representação identitárias.

- Navegação transparente: certificar-se que os recursos para a navegação durante a atividade sejam claros e consistentes; oferecer uma navegação interativa e intuitiva; tornar os recursos de auxilio a navegação claros e intuitivos; oferecer recursos de orientação e localização em ambientes virtuais.

- Controles para o usuário: oferecer o controle para a progressão durante o jogo através da escolha de dificuldade de jogo; oferecer recursos de customização de controles; assegurar que todas as funcionalidades sejam claras e intuitivas.

- Robustez: tornar fácil a negociação de erros e consequências; assegure-se que a interface do jogo responda a ações do jogador; ofereça funcionalidades de save game para que o jogador possa retomar seu jogo de um ponto prévio ou de onde parou; oferecer recursos de ajuda contextualizados ao ambiente do jogo.

- Interface visual apropriada: tornar a interface simples, organizada e visualmente agradável; tornar a informação ou conteúdo instrucional visualizável por meio de fases ou níveis; assegurar a consistência dos elementos que compõem a interface do jogo; assegurar que os gráficos ou os elementos de mídia apresentados ao aprendiz/jogador tenham um propósito; tornar o conteúdo textual claro e legível. ${ }^{17}$

Tais critérios ajudam a estabelecer diretrizes e ações práticas para uma experiência de jogo mais consistente com os objetivos de aprendizado propostos. Como já antes mencionado, esses elementos de interface, interação e jogabilidade se orientam no sentido de alinhar a experiência de jogo a um conteúdo programático específico de forma a diminuir a possibilidade de se tornar um mero acessório de entretenimento em sala de aula. Certamente, outros elementos devem ser observados para que tais atividades cumpram com os propósitos estabelecidos numa grade curricular e assegurem, por exemplo, que haja um balanceamento criterioso entre o que é compreendido como aprendizado formal - o aprendizado de conteúdos específicos - ou o que é uma mera proposta lúdica desalinhada (Conolly; 2010:28-31).

Levando-se em conta a abordagem teórica aqui utilizada, pode-se perceber que as diferentes teorias tanto educacionais quanto de jogos podem ser combinadas de diversas formas para a construção de interfaces metodológicas que atendam a fins educacionais bem específicos. Entretanto, há ainda outro aspecto a ser considerado, a saber, o dos diferentes tipos de jogos que podem integrar um projeto didático que os considere como incremento para o desenvolvimento

\footnotetext{
16 Em outras palavras, oferecer recursos de comunicação do tipo TeamSpeak Client (bate-papos in-game em tempo real).

17 Tradução nossa.
} 
de habilidades cognitivas paralelas e como recurso para a construção de uma proposta de aprendizado genuinamente significativa, assuntos que nortearão o capítulo seguinte.

\section{GAME-BASED LEARNING}

O Game-Based Learning (aprendizado centrado em jogos) é uma metodologia educacional que alia componentes curriculares a jogos com o objetivo de tornar mais dinâmica e atraente a instrução de conteúdos. Segundo Marc Prensky, referência na área de jogos e ensino e de letramento digital,

\footnotetext{
"é a combinação de dois fatores que tornam bem-sucedidas as boas iniciativas em Game-Based Learning: a motivação do jogo, que leva a uma imersão no aprendizado, e uma metodologia de ensino que se dá de como ágil, efetiva e absolutamente alheia ao modelo escolar clássico". $(2001: 14)^{18}$
}

Além de seu uso no ensino de conteúdos programáticos - Física, Química Matemática, Línguas Estrangeiras etc. - estes jogos podem ser utilizados como forma de desenvolver os chamados temas transversais - noções de política, cooperação, cidadania -, além é claro, de sua aplicação em iniciativas voltadas ao treinamento empresarial e institucional.

Neste capítulo, trataremos dos principais usos dessa interface educacional, mencionando e exemplificando alguns gêneros de jogos que podem ser utilizados em programas didáticos ancorados em técnicas de Game-Based Learning.

\subsection{Contextualização histórica}

Nos últimos anos, pudemos observar uma mudança do paradigma relacionado aos jogos digitais. Conceitos tradicionais de jogabilidade e interação mudaram, possibilitando ao jogador e aos desenvolvedores um universo novo de possibilidades de abordagens para a educação e para o treinamento de conteúdos instrucionais.

Além dessa mudança paradigmas de jogabilidade ${ }^{19}$, nota-se hoje também uma modificação na forma como os jogos são concebidos. Se antes eram produzidos a partir de

\footnotetext{
18 Tradução nossa.

19 A partir do aprimoramento das tecnologias de reconhecimento de movimentos, uma infinidade de propostas até então inconcebíveis por conta de limitações técnicas pode ser posta em prática para auxiliar, por exemplo, crianças
} 
métodos típicos - e não raras vezes exclusivos - de game design, hoje fazem uso de estratégias ancoradas em outras áreas do conhecimento. Um exemplo disso são os jogos cuja trama se estrutura de forma análoga às narrativas cinematográficas ${ }^{20}$, prendendo o jogador não só pela experiência lúdica que o jogo proporciona, mas também pela imersão que a trama emergente dentro do jogo possibilita (TAYLOR; 2010).

Mais antigo que o próprio conceito de videogame, a utilização e o desenvolvimento de iniciativas pautadas na utilização de simulações na forma de jogos para o treinamento militar data do início da década de 50 (1952, mais precisamente). A implementação inicial destas iniciativas se deu de forma tímida por conta dos recursos escassos da época e da falta de computadores, cujo uso se limitava a pesquisas relacionadas à segurança nacional e simulações estratégicas. Os esforços de pesquisa nesta área apresentaram um hiato até meados da década de 80, representando em sua maioria experimentos de treinamentos baseados em tecnologias analógicas. A partir deste momento, e assim como em seu momento inicial, a utilização de simulações eletrônicas com fins educacionais se construía com objetivos de uso militar, para o treinamento simulado de tropas de combate. Mais tarde estas mesmas iniciativas ganharam espaço no mercado de entretenimento através da migração de alguns de seus desenvolvedores para a indústria de videogames (BERGERON; 2006:4).

Ainda segundo Bergeron (ibid), o caminho pelo qual tais tecnologias foram desenvolvidas se deu em ambas as direções, representando ganhos para o campo da pesquisa bélica, de um lado, e a do entretenimento, do outro. A partir da década de 1990, a interseção entre essas duas indústrias gerou benefícios que hoje atingem o consumidor final na forma equipamentos de treinamento médico e no desenvolvimento de hardware de processamento gráfico, por exemplo.

Todavia, a continuidade de desenvolvimento e manutenção de iniciativas de educação baseadas em jogos ou simulações não dependia ainda neste momento histórico quase que em sua totalidade da indústria do entretenimento, mas de instituições militares e de pesquisa. Estas iniciativas estavam longe de representar o que hoje conceituamos como videogame, mas eram representadas por manequins automatizados para o treinamento médico, cabines de simulação de vôo, plataformas de treino de tiro, direção entre outras. Atualmente, muitos jogos atendem não somente ao mercado do treinamento técnico, mas também ao universo do entretenimento ou mesmo do mercado corporativo. Kuma War (Kuma Reality Games) e America's Army (United

com autismo a interagir de forma dinâmica com interfaces que antes eram complexas demais para elas. Um exemplo disso pode ser lido em http://jovemnerd.ig.com.br/jovem-nerd-news/games/kinect-e-a-crianca-com-autismo/

20 Alguns exemplos: Alan Wake's Nightmare (Remedy Entertainment); Assassins Creed (Ubisoft Montreal); L. A. Noire (Team Bondi); Heavy Rain (Quantic Dream). 
States Army) no âmbito dos jogos de guerra; simuladores médicos, militares e de segurança nacional desenvolvidos pela Breakway Games ${ }^{21}$; jogos corporativos e de gerenciamento de negócios do tipo tycoon games; simuladores científicos da University of Colorado ${ }^{22}$, além de diversas outras iniciativas as quais listaremos adiante. Essa tendência se estendeu a diversas outras áreas de pesquisa e fomento, algumas das quais focaram seus investimentos em softwares de treinamento e aprimoramento de profissionais da saúde, por exemplo, eliminando assim sua dependência com relação a centros de pesquisa militares, como acontecia num primeiro momento.

A evolução das tecnologias de produção de jogos aliada à miríade de aplicações que possibilitam e ao crescimento vertiginoso de sua indústria permitiu o surgimento de uma infinidade de classificações para os jogos digitais. Listamos abaixo alguns dos principais gêneros da atualidade. Convém elucidar que tal categorização não é nem fechada, já que alguns dos gêneros podem se combinar em um mesmo jogo, nem pacífica, visto que a questão da taxionomia no universo dos jogos digitais ainda é uma das mais debatidas, principalmente porque a metodologia para sua definição é bastante heterogênea ${ }^{23}$. Não citaremos exemplos de todos os gêneros, já que a lista de recursos ao final do artigo servirá a esse propósito. Optamos por apresentá-los em ordem alfabética:

\subsection{Advergames}

Também chamados advert-games, este desdobramento se caracteriza pelo uso de jogos com propósitos de divulgação de algum produto ou empresa no mercado. Além de seu conteúdo lúdico, estes jogos têm como objetivo consolidar a imagem de um produto dentro de um nicho de mercado específico. O primeiro registro formal deste tipo de jogo se dá em 1983, com o desenvolvimento e a distribuição do jogo Pepsi Invaders - uma versão do já conhecido Space Invaders produzida pela Atari sob encomenda para a Coca-Cola - para a plataforma Atari 2600 (Figura 1) ${ }^{24}$. Mais tarde, este conceito foi inserido dentro de outros jogos que não tinham como propósito específico a comercialização de um produto, mas que tinham como atrativo a referência a outras marcas e produtos já estabelecidos no mercado. Esta tática ganhou mais tarde o nome de in-game advertising, que constituía o uso de jogos eletrônicos como forma indireta de

\footnotetext{
21 www.breakawaygames.com

22 http://phet.colorado.edu

23 As classificações aqui apresentadas, hoje bastante difundidas, baseiam-se ora nos objetivos para os quais um jogo é produzido, ora nos usos efetivos de um jogo, ora em sua área de desenvolvimento, daí essa heterogeneidade.

${ }^{24}$ http://suamediasocial.com/2011/02/15/advergame-a-relacao-entre-publicidade-e-games/
} 
divulgação de um produto ou marca. Este conceito hoje é de grande valia para a indústria de desenvolvimento de jogos, uma vez que a divulgação de conteúdo publicitário em jogos representa uma fonte de renda substancial para seus desenvolvedores.

\subsection{Activism games}

Também chamados de jogos persuasivos (persuasive games), este desdobramento ocorre dentro de uma categoria maior que se refere ao que é chamado de games with an agenda (jogos com uma agenda politica, por exemplo). Estes jogos, de acordo com Bergeron (2006:27), são orientados para um público e uma área de influência específica. Esses jogos têm como premissa principal chamar a atenção do jogador para questões relacionadas a um posicionamento ideológico, como ocorre em Global Conflicts: Palestine (Serious Games Interactive, 2007), Peacemaker (ImpactGames, 2007), entre outros. A premissa principal para a categorização deste gênero é a de que videogames são ao mesmo tempo mídias expressivas e persuasivas. Eles representam a forma pela qual sistemas reais ou imaginados atuam e nos impelem a compreender a maneira pela qual nossas representações de mundo são construídas, aprendendo igualmente a nos posicionarmos de forma crítica com relação a elas (BOGOST; 2007:vii). É evidente que alguns jogos podem apresentar em seu conteúdo alguma proposta persuasiva, mesmo que seu discurso não assumidamente dessa natureza. Os jogos de guerra, de modo geral, se encaixam nessa descrição.

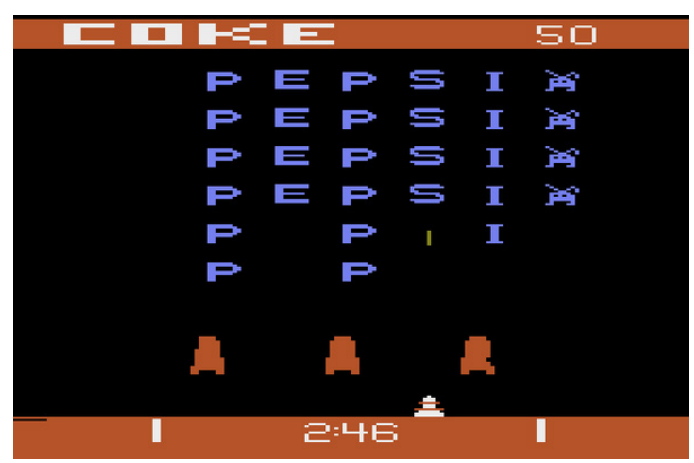

Figura 1 - Pepsi Invaders

\subsection{Artgames}


O conceito de jogo de arte não é exatamente muito claro. Ora definidos pela proposta estética subjacente a eles, ora por critérios puramente visuais, os art games, entretanto, são bastante populares e fazem uso de estratégias de imersão que primam pela valorização da experiência visual do jogador. Servem também à divulgação de propostas artísticas que não necessariamente pertencem ao universo dos jogos, mas que fazem uso dele para divulgar obras ou artistas específicos. Pac-Mondrian (Prize Budget for Boys) ${ }^{25}$, por exemplo, combina a estrutura de um dos jogos digitais mais famosos de todos os tempos a uma das mais conhecidas pinturas de Piet Mondrian, Broadway Boogie Woogie. Ainda nessa perspectiva de concepção de jogos a partir de obras reconhecidas, outro exemplo relevante é o de Echochrome (Sony; 2008), jogo comercial exclusivo da plataforma Sony PS $3^{\circledR}$ inspirado na obra do artista holandês Maurits Cornelis Escher $^{26}$, que faz uso de um modelo de jogabilidade bastante original.

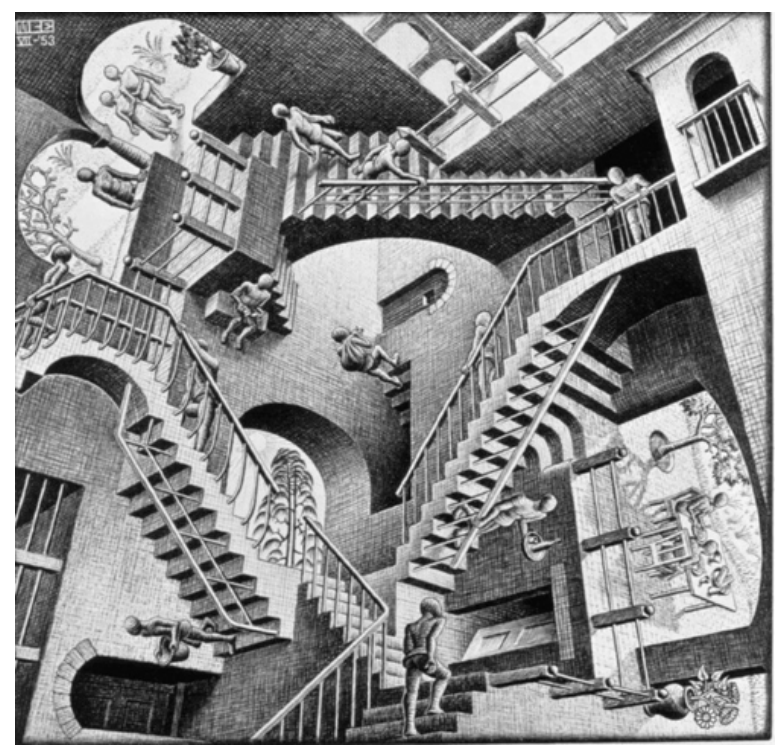

Figura 2 - "Relatividade", de Maurits Cornelis Escher

\footnotetext{
25 http://pbfb.ca/pac-mondrian/

26 http://www.worldofescher.com/gallery/A35L.html
} 


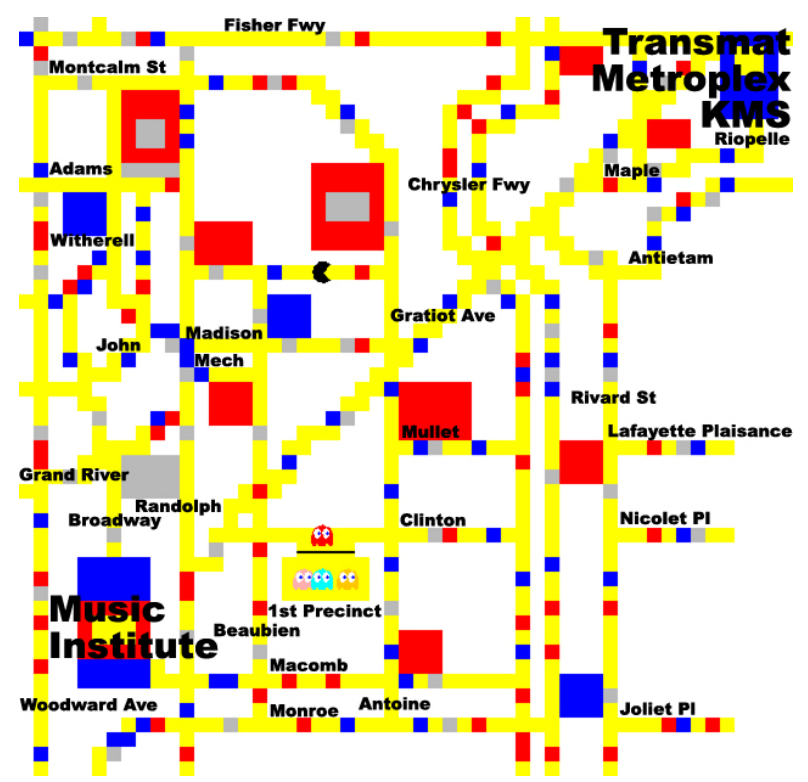

Figura 3 - Pac-Mondrian (Prize Budget for Boys )

\subsection{Business games}

Esta categoria tem seu foco principal no treinamento de ambientes corporativos, simulações de negócios e gestão empresarial. Planejamento, antecipação de riscos e resultados, controle de finanças e networking são alguns dos aspectos principais de qualquer empreendimento, sendo, portanto, cruciais para este tipo de jogo.

\subsection{Exergames}

Jogos cujo foco fundamental está na associação entre jogos e atividades corporais, através de simulação de exercícios físicos ou práticas mais específicas como fisioterapia, reabilitação física ou simples entretenimento. Vale ressaltar que esses usos que ultrapassam a esfera do mero entretenimento não são intrínsecos a esses jogos, mas acabaram sendo comumente associados a eles. Com a popularização do gênero para tais fins, observa-se o início de uma formalização da utilização desses jogos na área da saúde. A associação inglesa Parkinson's Disease Society of the United Kingdom, dedicada exclusivamente à busca de melhores condições 
de vida para portadores do mal de Parkinson, publicou recentemente um artigo ${ }^{27}$ sobre as benesses observadas em pacientes que se submeteram a tratamentos centrados no uso do Wii Fit ${ }^{\circledR}$, acessório da plataforma Nintendo Wii ${ }^{\circledR}$ (Figura 5).

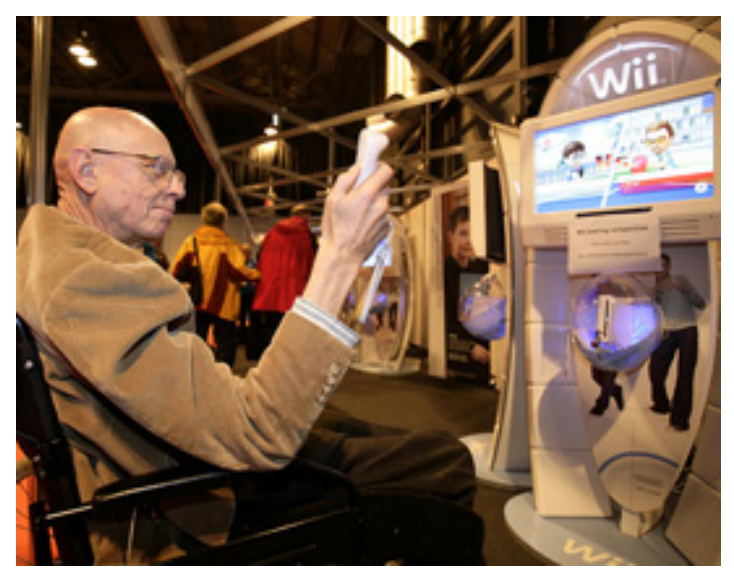

Figura 4 - Portador de Parkinson utilizando o Wii Fit ${ }^{\circledR}{ }^{28}$

\subsection{Newsgames}

Também chamados de jogos jornalísticos, são interações lúdicas digitais que tomam como pano de fundo para seu universo ficcional eventos reais ou recorrentes de uma temporalidade. Isto tem como objetivo, além de aumentar a interação do jogador através de um conteúdo real, como no caso de notícias, também informar o jogador acerca de um assunto ou divulgar um conteúdo científico ou meramente publicitário (ARAÚJO; 2010).

\subsection{Simulation games}

Sendo representativo das primeiras tentativas de utilização de jogos digitais para fins de aprendizado, os jogos de simulação caracterizam-se por imitar cenários ou situações que, de outra forma que não através de jogos, não permitiriam a negociação de consequências (o fracasso; a falha; a morte). Incluem-se neste gênero os jogos de simulação de vôo, tiro em primeira pessoa,

27

http://www.parkinsons.org.uk/advice/living_with_parkinsons/exercise_and_parkinsons/benefits_of_exercise/park insons_and_the_wii.aspx

28 A imagem encontra-se no endereço citado acima. 
treinamento militar, treinamento médico (em ambientes hospitalares ou em campo de batalha), gerenciamento de empresas, entre outros (BERGERON; 2006).

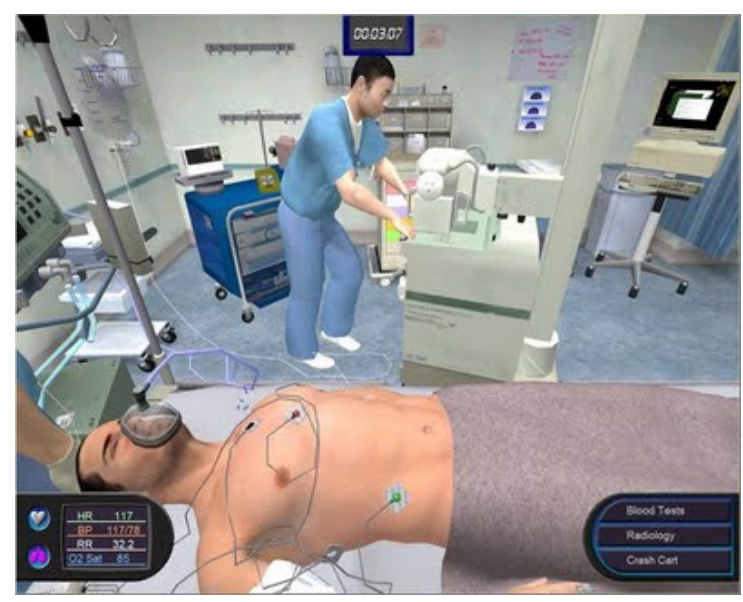

Figura 5 - Pulse (Breakaway Games) ${ }^{29}$

\section{CONSIDERAÇÕES FINAIS}

Como dissemos inicialmente, não tínhamos a pretensão - nem o espaço necessário para desenvolver exaustivamente todos os questionamentos propostos na introdução deste artigo. Havia, entretanto, um movimento fundador em nosso gesto de escrevê-lo, que era justamente o de aliar nossa própria experiência como jogadores e entusiastas dos jogos digitais a, primeiro, uma discussão embasada em teorias sobre as quais vínhamos discutindo há algum tempo e, segundo, ao desejo de compartilhar algumas das - em nosso julgamento - boas ferramentas lúdicas com as quais tivemos contato ao longo de nossa vivência tanto de jogadores como de professores. Foi, portanto, um trajeto de pesquisa indubitavelmente motivado pelo próprio prazer que o jogo proporciona.

O enriquecimento do caráter interdisciplinar que a utilização de jogos como ferramentas de aprendizado fomenta produz contribuições significativas não só para a consolidação de uma proposta curricular, mas também para o encaminhamento de uma discussão acerca da utilização de novas tecnologias como artefatos de aprendizado formais em um terreno que demonstra ter ainda bases teóricas movediças.

${ }^{29}$ http://www.breakawaygames.com 
A lista que apresentamos no capítulo seguinte corre o risco - inerente à web - de se tornar obsoleta ou desatualizada. Por conta da importância que atribuímos a ela e levando em consideração a peremptória condição de qualquer sítio eletrônico sobre o qual não tenhamos controle, manteremos uma versão constantemente atualizada no website Ludus ${ }^{30}$, que além de servir como espaço possível para a expansão deste artigo, dedica-se primordialmente a ampliar o debate acerca dos elementos que constituem o jogo - narrativa; análise de interação social; estrutura formal; game design - como elemento educador, como aspecto interdisciplinar e como fundamento cultural.

${ }^{30}$ www.ludus.ufsc.br 


\section{LISTA DE JOGOS, INSTITUIÇÕES DE PESQUISA E RECURSOS RELACIONADOS AO ENSINO BASEADO EM JOGOS}

\begin{tabular}{|c|c|c|c|c|}
\hline Grupo / Instituição / Jogo & Sítio eletrônico & Idiomas & Plataforma & Gratuito? \\
\hline $\begin{array}{l}\text { 3D Serious Games and Simulations: Empresa que desenvolve } \\
\text { soluções para e-learning baseadas em jogos. Os ambientes } \\
\text { desenvolvidos podem estar em conformidade com as especificações } \\
\text { SCORM e AICC. }\end{array}$ & http://www.3dseriousgamesandsimulations.com/ & Inglês & PC; Mac. & Não \\
\hline $\begin{array}{l}\text { Second Life: plataforma de desenvolvimento e interação em } \\
\text { ambientes virtuais online. }\end{array}$ & http://secondlife.com/?lang=pt-BR & Vários & PC & $\operatorname{Sim}$ \\
\hline $\begin{array}{l}\text { Global Conflicts: jogo que explora temáticas referentes à geografia e } \\
\text { história. O jogo oferece uma ampla variedade de materiais em formato } \\
\text { PDF para a exploração de temas transversais em sala de aula. }\end{array}$ & http://www.globalconflicts.eu/teachermaterial & Vários & PC & Não \\
\hline $\begin{array}{l}\text { GEPEMNT: Grupo de Estudos e Pesquisas em Educação Matemática } \\
\text { e Novas Tecnologias; UFMG. }\end{array}$ & http://www.mat.ufmg.br/gepemnt/ & Português & $\mathrm{N} / \mathrm{A}$ & $\mathrm{N} / \mathrm{A}$ \\
\hline $\begin{array}{l}\text { Art Games: portal que agrega diferentes jogos que prezam por uma } \\
\text { proposta artística, seja através de do visual de sua interface ou através } \\
\text { de uma proposta de jogabilidade. }\end{array}$ & http://www.artificial.dk/articles/artgamesnetworks.htm & Inglês & $\mathrm{N} / \mathrm{A}$ & Sim \\
\hline $\begin{array}{l}\text { Incredible Activities and Games: portal que agrega diferentes } \\
\text { atividades e jogos voltados ao estudo das Artes. }\end{array}$ & http://www.princetonol.com/groups/iad/links/artgames.html & Inglês & $\mathrm{N} / \mathrm{A}$ & Sim \\
\hline $\begin{array}{l}\text { Persuasive Games: portal que agrega vários jogos explorando } \\
\text { temáticas referentes a políticas públicas, publicidade, treinamento } \\
\text { corporativo, educação entre outros. }\end{array}$ & http://www.persuasivegames.com/games/ & Inglês & $\mathrm{N} / \mathrm{A}$ & $\begin{array}{l}\text { Depende } \\
\text { de cada } \\
\text { jogo. }\end{array}$ \\
\hline $\begin{array}{l}\text { Tríade: jogo brasileiro desenvolvido para explorar noções de histórias } \\
\text { referentes ao século XVIII com foco na Revolução Francesa. }\end{array}$ & http://www.comunidadesvirtuais.pro.br/triade/ & Português & PC & Sim \\
\hline $\begin{array}{l}\text { JECRIPE: jogo de Estímulo a Crianças com Síndrome de Down com } \\
\text { em Idade Pré-Escolar com suporte para WiiMote®; UFF }\end{array}$ & http://www.jecripe.com/ & Português & $\mathrm{N} / \mathrm{A}$ & $\operatorname{Sim}$ \\
\hline $\begin{array}{l}\text { Peacemaker: jogo de estratégia que explora o conflito entre Israel e } \\
\text { Palestina e os assuntos referentes a essa temática. }\end{array}$ & http://www.peacemakergame.com/ & $\begin{array}{l}\text { Inglês; Árabe; } \\
\text { Hebraico. }\end{array}$ & PC; Mac. & Não \\
\hline $\begin{array}{l}\text { Earthquake in Zipland: jogo projetado especificamente para ajudar } \\
\text { crianças cujos pais entraram em divórcio ou separação judicial. }\end{array}$ & http://www.ziplandinteractive.com/ & Inglês. & PC & Não \\
\hline
\end{tabular}


Food Force: jogo que explora temáticas referentes à fome global e ao gerenciamento de distribuição de recursos durante crises humanitárias.

The Organizing Game: jogo que possibilita explorar temáticas referentes a ativismo social e liderança comunitária, entre outras.

PHET: sítio que agrega várias simulações de fenômenos referentes às áreas de Física, Química, Biologia, Matemática e Ciências da Terra.

Thinking Worlds: ferramenta de autoria rápida e fácil para a criação

de ambientes 3D.

Engage Learning: portal de pesquisa que se propõe a catalogar vários jogos de acordo com objetivos de aprendizado específicos, faixa etária de usuário, nível de escolaridade, plataforma de jogo, tempo de jogo e gênero (verificar a seção "Sample Games and Good Practice Examples").

GameMaker: plataforma de desenvolvimento de jogos com interface intuitiva. Este aplicativo permite o desenvolvimento de jogos para sítios online e dispositivos móveis.

Adobe Captivate: software de autoria de conteúdos e-learning que permite a criação de apresentações, jogos, screencasts e tutoriais que estejam em conformidade com as especificações SCORM.

Serious Games Interactive: portal que agrega diferentes jogos para uso acadêmico, ensino médio e fundamental com temáticas relativas a educação e cultura, saúde, conflitos globais, história, etc.

Eve Online: jogo multiplayer de simulação espacial com um complexo sistema de economias que pode ser explorado através de atividades temáticas relacionadas a gerenciamento, economia, planejamento, política, narrativas textuais etc.

\section{Jogos de tiro em primeira pessoa (first person shooters): muitas}

referências sugerem o uso de tais jogos para o desenvolvimento de

habilidades cognitivas paralelas (coordenação motora, planejamento,

senso de direção, estratégia e outras). Eis alguns dos mais populares.

50 great sites for serious, educational games: repositório contendo várias sugestões de sítios e jogos que exploram áreas temáticas distintas para serem trabalhadas em sala de aula.

\begin{tabular}{|c|c|c|c|}
\hline http://www.food-force.com/ & Vários & PC & Sim \\
\hline http://www.organizinggame.org/ & Inglês; Espanhol. & PC & Sim \\
\hline http://phet.colorado.edu/en/simulations/ & Vários. & $\begin{array}{l}\text { Independente } \\
\text { (jogos em Java) }\end{array}$ & Sim \\
\hline http://www.thinkingworlds.com/ & Inglês & PC & $\begin{array}{l}\text { Sim (com } \\
\text { limitações) }\end{array}$ \\
\hline http://www.engagelearning.eu & Inglês & Várias & Sim \\
\hline http://www.yoyogames.com/make & Inglês & $\begin{array}{l}\text { PC; Mac; } \\
\text { HTML5 } \\
\text { (independente de } \\
\text { plataforma) }\end{array}$ & Não \\
\hline http://www.adobe.com/br/products/captivate.html & Vários & PC; Mac. & Não \\
\hline http://www.seriousgames.dk & Vários & $\begin{array}{l}\text { Pc; Mac; } \\
\text { Android; iOS. }\end{array}$ & $\begin{array}{l}\text { Depende } \\
\text { de cada } \\
\text { jogo. }\end{array}$ \\
\hline http://www.eveonline.com/ & Vários & PC; Mac. & Não \\
\hline $\begin{array}{l}\text { http://www.callofduty.com/ } \\
\text { http://www.battlefield.com/ } \\
\text { http:// combatarms.nexon.net/ } \\
\text { http://www.csonlinebr.net/ }\end{array}$ & Vários & $\begin{array}{l}\text { PC; Mac; } \\
\text { Playstation; } \\
\text { Nintendo Wii; } \\
\text { XBox. }\end{array}$ & Não \\
\hline $\begin{array}{l}\text { http://www.onlinecolleges.net/2009/08/17/50-great-sites-for- } \\
\text { serious-educational-games/ }\end{array}$ & Vários & Várias & $\begin{array}{l}\text { Depende } \\
\text { de cada } \\
\text { jogo. }\end{array}$ \\
\hline
\end{tabular}


Banco Internacional de Objetos Educacionais: repositório com

objetos educacionais de acesso público, em vários formatos e para

todos os níveis de ensino. 


\section{REFERÊNCIAS}

\subsection{Bibliografia citada}

AGAMBEN, Giorgio. Infanzia e storia. Distruzione dell'esperienza e origine della storia. Torino: Einaudi, 1979.

ARAÚJO, Daniela Camila de. Jogar para informar: Uma análise dos newsgames como linguagem na divulgação científica. 2010. Monografia. Curso de Comunicação Social / Jornalismo, UFV, Viçosa - MG.

BERGERON, Bryan. Developing serious games. Hingham, Massachusetts: Charles River Media, 2006.

BOGOST, Ian. Persuasive games: the expressive power of videogames. Cambridge, Massachusetts: The MIT Press, 2007.

CAILLOIS, Roger. Los juegos y los hombres: La máscara y el vértigo. México: Fondo de Cultura Econômica, 1986.

CONOLLY, Thomas; STANSFIELD, Mark; BOYLE, Liz. Games-Based Learning Advancements for Multi-Sensory Human Computer Interfaces: Techniques and Effective Practices. Nova York: Information Science Reference, 2009.

DERRYBERRY, Anne. Dispatch from the Digital Frontier: Games as Meaning Makers. Learning Solutions Magazine. 28 set 2010. Disponível em < http://www.learningsolutionsmag.com/articles/525/dispatch-from-the-digital-frontier-games-asmeaning-makers > Acesso em 08 jun 2011.

GEE, James Paul; MORGRIDGE, Tashia. Good Video Games and Good Learning. Madison: University of Wisconsin, 2009. Disponível em <

http://www.academiccolab.org/resources/documents/Good_Learning.pdf >. Acesso em 10 out 2011.

GRABINGER, R. Scott; DUNLAP, Joanna C. Rich environments for active learning: a definition. Association for Learning Technology Journal, vol. 3, no 2, 1995, p. 5-34

HUIZINGA, Johan. Homo Ludens. 4ª ed. São Paulo: Perspectiva, 2000.

KNOWLES, Malcolm S. The Adult Learner: A Neglected Species. $6^{\text {a }}$ ed. Houston: Gulf Publishing Company, 2005.

MOITA, Filomena Ma. G. da Silva Cordeiro. Jogos eletrônicos contexto cultural: curricular juvenil de "saber de experiência feito". Disponível em < http://www.uff.br/emdialogo/documento/jogos-eletrônicos-contexto-cultural-curricularjuvenil-de-saber-de-experiência-feito > Acesso em 10 out 2011.

PELIZZARI, A.; KRIEGL, M.L.; BARON, M.P.; FINCK, N.T.L \& DOROCINSKI, S. I. Teoria da Aprendizagem Significativa Segundo Ausubel. Revista PEC, Curitiba, v. 2, n. 1, p. 37-42, jul 2001 / jul 2002. 
PRENSKY, Marc. Digital Game-Based Learning. Nova Iorque: McGraw-Hill, 2001. Disponível em < www.marcprensky.com/writing/prensky\%20-\%20ch1-digital\%20gamebased $\% 20$ learning.pdf $>$. Acesso em 10 out 2011.

RYAN, Marie-Laure. Narrative as Virtual Reality: Immersion and Interactivity in Literature and Electronic Media. Baltimore, Maryland: Paralllax, 2001.

SALEN, Katie; ZIMMERMAN, Eric. Rules of Play: Game Design Fundamentals. Cambridge, Massachusetts: The MIT Press, 2004.

SIMKINS, D, W; STEINKUEHLER, C. Critical Ethical Reasoning and Role-Play. Games and Culture. vol. 3, jul 2008, pp. 333-355.

TAYLOR, Leanne C. History, Mystery and Story: Games and the 10 Minute Rule. Disponível em $<$ http://www.gamasutra.com/view/feature/6208/history_mystery_and_story_games_.php > Acesso em 10 set 2011.

WHITTON, Nicola. Learning with Digital Games: A Practical Guide to Engaging Students in Higher Education. Nova York: Routledge, 2010.

\subsection{Bibliografia consultada}

BOGOST Ian; FERRARI, Simon; SCHWEIZER, Bobby. Newsgames: Journalism at Play. Cambridge, Massachusetts: The MIT Press, 2010.

CARLISLE, Rodney P. Encyclopedia of Play in Today's Society. Londres: SAGE Publications, 2009.

CHANG, Maiga; KUO, Rita. Learning by Playing. Game-based Education System Design and Development: 4th International Conference on E-learning, Edutainment 2009, Banff, Canada, proceedings. Berlim: Springer, 2009.

HJORTH, Larissa; CHAN, Dean. Gaming Cultures and Place in Asia-Pacific. Londres: Routledge, 2009.

KNOWLES, Malcolm S.; HOLTON III, Elwood F.; SWANSON, Richard A. The Adult Learner: The Definitive Classic in Adult Education and Human Resource Development. $6^{a}$ ed. Amsterdã: Elsevier, 2009.

MATTAR, João. Games em Educação: como os nativos digitais aprendem. São Paulo: Pearson Prentice Hall, 2010.

MAYRA, Frans. An Introduction to Game Studies: games in culture. Londres: SAGE Publications, 2008.

MOSELEY, A. (2008), An Alternative Reality for Higher Education? Lessons to be learned from online reality games. IN: ALT-C. 2008, Leeds, UK, 9-11th September 2008 
PIVEC, Maja. Affective and Emotional Aspects of Human-Computer Interaction: Game and Innovative Learning Approaches: Volume 1, Future of Learning. Amsterdã: IOS Press, 2006.

SALEN, Katie. The Ecology of Games - Connecting Youth, Games, and Learning.

SCHEINES, Graciela. Juegos Inocentes, Juegos Terribles. Buenos Aires: Eudeba, 1998.

SCHEINES, Graciela. Juguetes y jugadores. Buenos Aires: Editorial de Belgrano, 1981.

SUTTON-SMITH, Brian. The Ambiguity of Play. Cambridge: Harvard University Press, 2001.

SWIRSKI, Peter. Of Literature and Knowledge: Explorations in Narrative Thought

Experiments, Evolution, and Game Theory. Routledge, 2007.

VÉNTSEL, E. S. Elementos de La Teoría de Los Juegos. Moscou: Editorial MIR, 1977. 